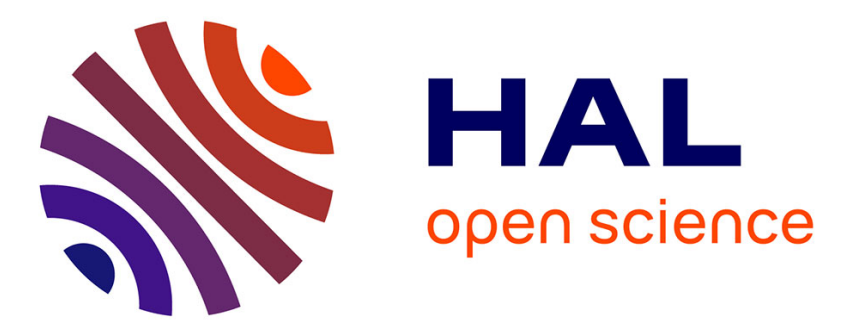

\title{
Coupled effect of loading frequency and amplitude on the fatigue behavior of advanced sheet molding compound (A-SMC)
}

Mohammadali Shirinbayan, Joseph Fitoussi, Fodil Meraghni, Benjamin

Surowiec, M.A. Laribi, Abbas Tcharkhtchi

\section{To cite this version:}

Mohammadali Shirinbayan, Joseph Fitoussi, Fodil Meraghni, Benjamin Surowiec, M.A. Laribi, et al.. Coupled effect of loading frequency and amplitude on the fatigue behavior of advanced sheet molding compound (A-SMC). Journal of Reinforced Plastics and Composites, 2017, 36 (4), pp.271282. $10.1177 / 0731684416682853$. hal-02413207

\section{HAL Id: hal-02413207 \\ https://hal.science/hal-02413207}

Submitted on 16 Dec 2019

HAL is a multi-disciplinary open access archive for the deposit and dissemination of scientific research documents, whether they are published or not. The documents may come from teaching and research institutions in France or abroad, or from public or private research centers.
L'archive ouverte pluridisciplinaire HAL, est destinée au dépôt et à la diffusion de documents scientifiques de niveau recherche, publiés ou non, émanant des établissements d'enseignement et de recherche français ou étrangers, des laboratoires publics ou privés. 


\title{
Coupled effect of loading frequency and amplitude on the fatigue behavior of advanced sheet molding compound (A-SMC)
}

\author{
M Shirinbayan', J Fitoussi ', F Meraghni ${ }^{2}$, B Surowiec ${ }^{3}$, M Laribi ${ }^{1}$ \\ and A Tcharkhtchi'
}

\begin{abstract}
This paper presents the experimental results of tension-tension stress-controlled fatigue tests performed on advanced sheet molding compound (A-SMC). It aims at analyzing the effect of fiber orientation, loading amplitude, and frequency on the fatigue response and the related temperature evolution due to the self-heating phenomenon. Two types of A-SMC have been analyzed: randomly oriented (RO) and highly oriented (HO). The coupled effect of the loading amplitude and the frequency has been studied. It has been shown that the couple frequency-amplitude affects the nature of the fatigue overall response which can be governed by the damage mechanisms accumulation (mechanical fatigue) and/or by the self-heating (induced thermal fatigue). For fatigue loading at $100 \mathrm{~Hz}$, self-heating has been observed and yielded to a temperature rise up to $70^{\circ} \mathrm{C}$. The latter causes a decrease of the storage modulus related to the $\beta$-transition of the vinylester. It has been demonstrated that the self-heating produced a material softening and decreased the fatigue life. SEM observations revealed that the samples tested at $100 \mathrm{~Hz}$, exhibit smooth debonding surfaces due to the induced thermal softening of the matrix whereas more brittle fracture of the matrix surrounding fibers is observed during the fatigue tests achieved at $10 \mathrm{~Hz}$.
\end{abstract}

\section{Keywords}

Advanced SMC composite, fatigue strength, damage, self-heating, induced thermal fatigue, experimental analysis

\section{Introduction}

Sheet molding compounds (SMCs) are commonly used in automotive industry for light-weight structural component with an improvement of the thermomechanical performance to cost ratio. These composites are ideal for large structural automotive components owing to their high strength-to-weight ratio. ${ }^{1-3}$ Recently, a new advanced SMC (A-SMC) composite has been developed by Plastic-Omnium as innovative solution for automotive components such as the new generation of tailgate or the new automotive front floor module. A-SMC combines short glass fiber/bundles and vinylester thermoset which exhibit many desirable features, including mechanical properties, excellent chemical resistance and tensile strength, and cost competitiveness. A-SMCs are high strength glass reinforced thermoset molding materials processed by thermo-compression. ${ }^{4-6}$
Composite design in the case of fatigue loading is usually characterized by a $\mathrm{S}-\mathrm{N}$ curve, by which one may obtain the Wöhler curve. ${ }^{7}$ This later can be presented as a curve giving the value of a cyclic stress amplitude, $\sigma_{\max }$ versus the number of cycles to failure $\mathrm{N}_{\mathrm{r}}$. Fiber orientations and the related process induced microstructure, ${ }^{8}$ nature of matrix, applied stresses, temperature, frequency, and induced self-heating

\footnotetext{
'Arts et Métiers ParisTech, PIMM-UMR CNRS 8006, Paris, France

${ }^{2}$ Arts et Métiers ParisTech, LEM3-UMR CNRS 7239, Metz, France

${ }^{3}$ PLASTIC Omnium Auto Exterior, Sigmatech, Sainte Julie, France

Corresponding author:

M Shirinbayan, Arts et Métiers ParisTech, PIMM-UMR CNRS 8006, I5I Boulevard de l'Hôpital, 750I3 Paris, France.

Email: mohammadali.shirinbayan@ensam.eu
} 
phenomenon or environmental effects are appropriated aspects that have to be taken into account to reliably estimate the fatigue life of short fiber reinforced polymer composites. ${ }^{7-9}$

Fleckenstein et al. ${ }^{10}$ performed experimental investigation on SMC samples with different preferred fiber orientations. As expected, experimental results showed that the specimens with predominantly $0^{\circ}$ fiber alignment have the highest fatigue strength.

Wang et al. ${ }^{11}$ have shown that increasing the applied fatigue stress $\sigma_{\max }$ leads to a higher stiffness reduction rate and shorter fatigue life.

To study the cyclic loading frequency (f) effect, Handa et al. ${ }^{12}$ performed a study of fatigue behavior on glass fiber-reinforced polyamide at different frequencies ranging from 5 to $50 \mathrm{~Hz}$ and showed that increasing the frequency decreases the fatigue life and strength. Different authors ${ }^{13-14}$ studied the effect of frequency during the fatigue test of nylon 66 reinforced with $30 \%$ short glass fibers and concluded that, for the frequency higher than $2 \mathrm{~Hz}$, the rate of crack initiation and growth increase, leading to the decrease of life time. The self-heating is related directly to the viscoelastic nature of matrix and to the dissipated energy during fatigue tests. Indeed because of self-heating the matrix may passes from glassy state (high modulus) to rubbery state (low modulus).

Especially at high frequencies, when temperature rise due to self-heating is significant. This aspect has been noticed notably for short fiber-reinforced thermoplastic composites. ${ }^{13-15}$ For instance, for polyamide 66 reinforced with short glass fiber, several works have shown that for low frequencies, there was only an effect of the mechanical loading, whereas for high frequencies a coupling between mechanical and thermal effects were observed and evidenced. ${ }^{15}$ SEM micrographs showed that the matrix remained ductile locally around fibers before debonding. ${ }^{13-15}$ From a macroscopic point of view, evolution of the slope of the hysteresis loop is a common indicator of damage that occurs in reinforced thermoplastic composites. ${ }^{15,16}$

One can notice that the coupled effect of loading frequency and amplitude on the fatigue has never been addressed for SMC composites.

For random short glass fiber-reinforced polymer composite subjected to cyclic loading, it has been shown that dynamic fatigue behavior brings about a diffuse crack initiation and growth which leads consequently to a stiffness reduction. ${ }^{17}$ Based on experimental results, a damage parameter ${ }^{17,18}$ was introduced to quantify the fatigue damage as

$$
\mathrm{D}=1-\mathrm{E} / \mathrm{E}_{0}
$$

where $E_{0}$ is the initial Young's modulus and $\mathrm{E}$ is the residual Young's modulus of the damage material. Normalized stiffness reduction as a function of inelastic density of energy was proposed and described by Launay et al. ${ }^{19}$ for short glass fiber-reinforced polyamide under cyclic loading. This energy was defined as the difference between the total mechanical energy and the elastic strain energy. Cyclic stiffness softening has been successfully correlated to the inelastic energy density, and may stand for material progressive degradation. Damage development can be characterized by a more or less stabilized temperature and Young's modulus. Moreover, fatigue life prediction requires thorough understanding of the damage mechanisms. ${ }^{20-24}$

In the present paper, an experimental study is carried-out to investigate the influence of fiber orientation as well as the coupled effect of the cyclic loading amplitude and frequency on the fatigue behavior and the induced self-heating of A-SMC.

The organization of this work is as follows: Material description and methods section is devoted to a description of the main physical characteristics and the process-induced microstructure of A-SMC composite as well as the developed experimental procedure for fatigue testing at several frequencies. In Experimental results and discussion section, experimental results obtained under quasi-static and fatigue loading are presented and discussed in terms of coupled effect of the fatigue loading amplitude and the frequency. The nature of the fatigue overall response that can be mechanical fatigue (MF) and/or induced thermal fatigue (ITF) and analyzed in terms of SEM observations and are related to the loading conditions governing the self-heating phenomenon. Concluding remarks are given in Conclusion section to summarize the main experimental findings to highlight the coupled effect of loading frequency and amplitude on the fatigue and its relation with the induced self-heating occurring.

\section{Material description and methods}

\section{Advanced sheet molding compound composite (A-SMC)}

A-SMC consists of a vinylester matrix with a high content of glass fibers $(50 \%$ in mass corresponding to $38.5 \%$ in volume) as given in Table 1 .

Raw material is nonconsolidated, flexible, and stored on rolls. The sheets are cut from these rolls with adapted size depending on the mold. Then, several layers should be stacked into the mold. The material consolidation is performed by thermo-compression process $\left(150^{\circ} \mathrm{C}\right.$ at $\left.60-120 \mathrm{~kg} / \mathrm{cm}^{2}\right)$. Under these conditions the viscosity of the vinylester decreases and allows fulfill the whole cavity of the mold; this is the first step 
Table I. A-SMC composition and the constituents weight content.

\begin{tabular}{ll}
\hline Product nature & $\begin{array}{l}\text { Composition } \\
\text { (content in mass percent) }\end{array}$ \\
\hline Glass fibers & $50 \%$ \\
Vinyl-ester resin & $24 \%$ \\
Filler & $24 \%$ \\
Other products & $2 \%$ \\
\hline
\end{tabular}

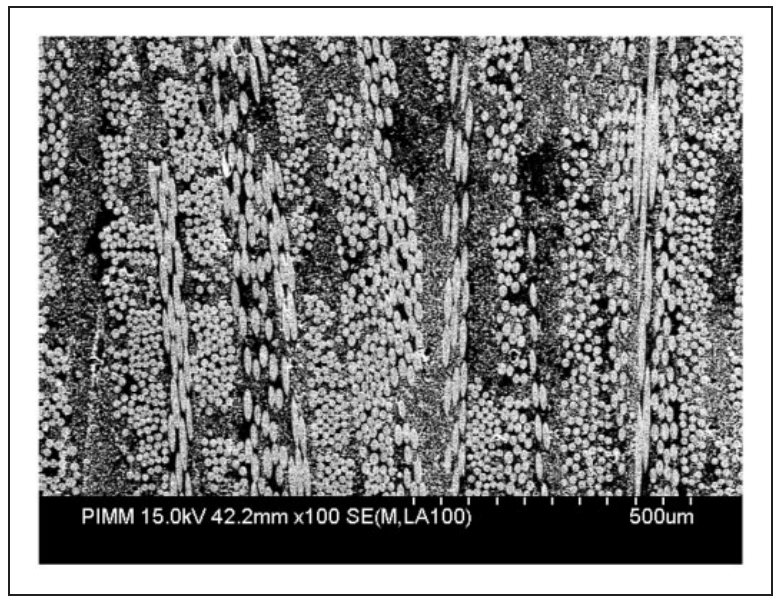

Figure I. Typical microstructure of A-SMC observed by mean of a SEM: randomly oriented bundle of fibers.

of the manufacturing process. Then, the material stays in position without reticulation for a short duration; this is the second step. The third step of the process consists of a reticulation time of the thermoset polymer during the consolidation phase. The duration of the whole process for one part is less than 2 min which is mandatory for automotive applications due to the required high production rate.

Figure 1 shows the typical A-SMC microstructure observed on a polished surface. The bundle of fibers can be oriented due to the polymer flow during compression. The fibers are presented as bundles of constant length $(\mathrm{L}=25 \mathrm{~mm})$. Each bundle contains approximately 250 glass fibers of about $15 \mu \mathrm{m}$ diameter. Microscopic observations, using scanning electronic microscope (HITACHI 4800 SEM), have been performed in order to investigate qualitatively the material microstructure and especially the fibers orientation.

Two types of A-SMC plates have been provided by Plastic-Omnium Auto Exterior: randomly oriented (RO) and highly oriented (HO) plates. HO plates have been obtained by an initial charge putting only in the left part of a rectangular mold $\left(30 \times 40 \mathrm{~cm}^{2}\right)$ before compression leading to an oriented material flow. RO plates were obtained without significant material flow by completely filling the mold. The fiber distribution in the RO and $\mathrm{HO}$ plates as a function of the cutting orientation has been characterized and presented in a previous work. ${ }^{6}$ It is worth noting that for both studied configurations ( $\mathrm{RO}$ and $\mathrm{HO}$ ), it can be assumed that, most of the fibers remain on the plane of the plate. Nevertheless, for the highly oriented (HO) plates, due to the polymer flow, fibers tend to be oriented parallel to the mold flow direction (MFD) before compression.

\section{Methods and experimental procedure}

DMTA characterization. Besides the SEM microscopic observations thermo-mechanical (DMTA) flexural tests have been achieved to measure the main transitions temperatures on RO samples using DMA Q800 instrument from TA Company. The flexural test has been realized at following condition: temperature range varying from $0^{\circ} \mathrm{C}$ to $250^{\circ} \mathrm{C}$, temperature rate of $2^{\circ} \mathrm{C} / \mathrm{min}$, and a frequency of $1 \mathrm{~Hz}$.

Fatigue tests. Tension-tension stress-controlled fatigue tests have been performed at different applied maximum stress $\left(\sigma_{\max }\right)$ on a MTS 830 hydraulic fatigue machine. The minimum applied stress $\left(\sigma_{\min }\right)$ is always chosen to be equal to $10 \%$ of the maximum applied stress. The chosen stress-ratio is thus $\left(R_{\sigma}=0.1\right)$ and the mean stress-level is equal to $0.55 \sigma_{\max }$.

In this paper, the results of experiments performed at different frequencies, namely $10,30,50$, and $100 \mathrm{~Hz}$ are presented. In order to measure precisely the stiffness reduction due to the first loading stage (initial damage), each fatigue test is preceded by a quasistatic tensile loading-unloading-elastic reloading stage. During cyclic loading, the temperature rise, due to the material self-heating, has been measured on the surface of the specimen using an infrared camera (RayngerMX4). The damage evolution has been estimated through the measurement of the Young's modulus evolution.

In a previous study, ${ }^{6}$ a recursive optimization procedure results in the determination of the specimen's optimal geometrical parameters adopted for high speed tensile tests. To this aim, a FE simulation assuming that the specimen behaves like an anisotropic solid, is performed and leads to the optimized geometry showed in Figure 2 which allows reducing the perturbations due to stress waves effect, in order to generate homogeneous stress and strain field and a constant high strain rate.

In this work, the experimental fatigue tests have been performed at room temperature on the same sample geometry. Fatigue experiments have been 


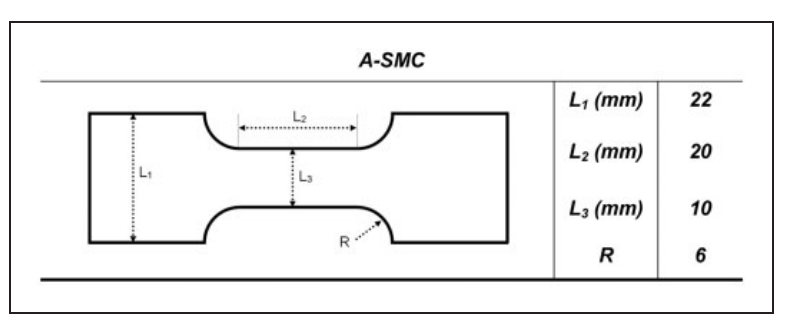

Figure 2. Optimized specimen geometry and its related dimensions.

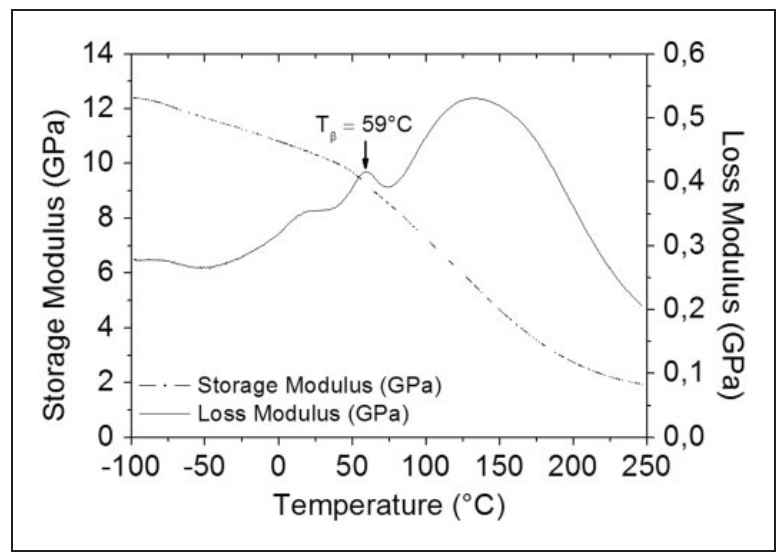

Figure 3. DMTA scan showing the types of transitions for RO-A-SMC sample.

achieved at different load directions, applied maximum stress (ranging from $35 \%$ to $80 \%$ of the material UTS noted hereafter as $\sigma_{\mathrm{r}}$ ) and frequencies (ranging from 10 to $100 \mathrm{~Hz}$ ).

\section{Experimental results and discussion}

\section{Thermo-mechanical properties}

To measure the main transition temperatures due to molecular mobility as a function of the temperature, DMTA tests have been performed on RO samples. Figure 3 shows the evolution of the storage and loss moduli versus temperature.

As it can be noticed, A-SMCs present at least three distinct transition zones in the temperature range of $0^{\circ} \mathrm{C}-250^{\circ} \mathrm{C}$. The first zone, extended between $70^{\circ} \mathrm{C}$ and $200^{\circ} \mathrm{C}$, is indeed the $\alpha$-transition, related to the glass transition of A-SMC. The value of $T_{\alpha}$ is nearly $130^{\circ} \mathrm{C}$. This extent of the glass transition region can be explained by the effect of

- The chemical modification of the matrix during DMTA test. In fact, when the cross-linking of the polymer matrix, namely vinylester resin is not

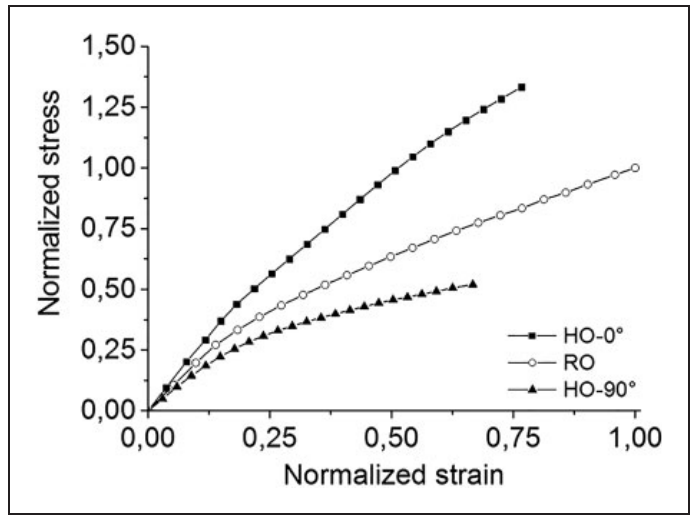

Figure 4. Normalized quasi-static tensile behavior of A-SMC composite at room temperature. One can mention that normalized stress (respectively strain) $=$ stress (respectively strain)/ultimate stress (respectively strain) obtained for tests performed on RO-A-SMC serving as a reference.

completed, the post cross-linking during DMTA test prevents sudden decrease of the modulus in the glass transition region.

- The presence of glass fibers which may prevent the sudden drop of the elastic modulus in the glass transition region.

The second transition corresponds to the $\beta$-transition with a $\mathrm{T}_{\beta}$ almost $59^{\circ} \mathrm{C} . \mathrm{T}_{\beta}$ is known as a brittle-ductile transition for amorphous polymers and it is generally related to the mobility of the small segments of molecular chains.

The third transition corresponds to $\gamma$-transition with a $\mathrm{T}_{\gamma}$ equal to $18^{\circ} \mathrm{C}$. The origin of this transition has not been clearly identified. DMTA results will be very helpful to analyze the induced self-heating phenomenon and to relate it to the measured temperature rise during fatigue test at different amplitude and frequencies.

\section{Quasi-static tensile behavior}

Effect of fiber orientation. Figure 4 shows the results of quasi static tensile tests on $\mathrm{HO}-0^{\circ}, \mathrm{RO}$, and $\mathrm{HO}-90^{\circ}$ samples at room temperature. As it can be seen, the value of Young's modulus of $\mathrm{HO}-0^{\circ}$ is about $18.5 \mathrm{GPa}$ which is higher than those of RO $(14.5 \mathrm{GPa})$ and $\mathrm{HO}-90^{\circ}(12.5 \mathrm{GPa})$ samples. The failure stress also highly depends on the fibers orientation. Failure stress of $\mathrm{HO}-0^{\circ}$ is about three times higher than that of HO- $90^{\circ}$ samples.

Effect of temperature. In order to show the effect of temperature on the mechanical properties of randomly oriented and highly oriented samples, tensile tests have 


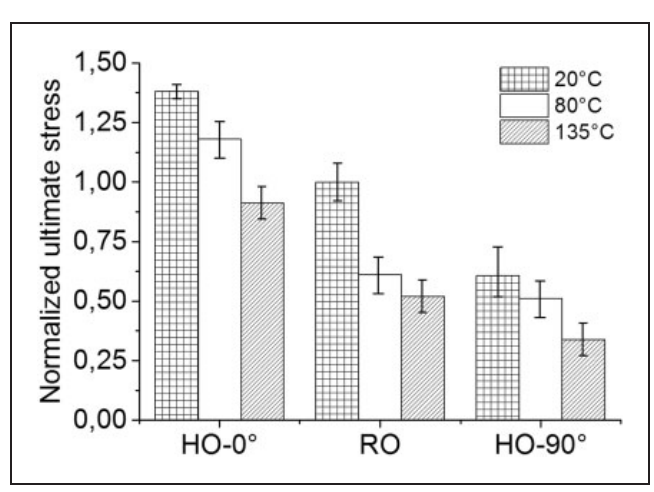

Figure 5. Normalized ultimate stress of oriented and nonoriented samples at $20^{\circ} \mathrm{C}, 80^{\circ} \mathrm{C}$, and $135^{\circ} \mathrm{C}$; (normalized value $=$ current value/average ultimate stress $\left(\sigma_{r}\right)$ value obtained for tests performed at $20^{\circ} \mathrm{C}$ on RO-A-SMC).

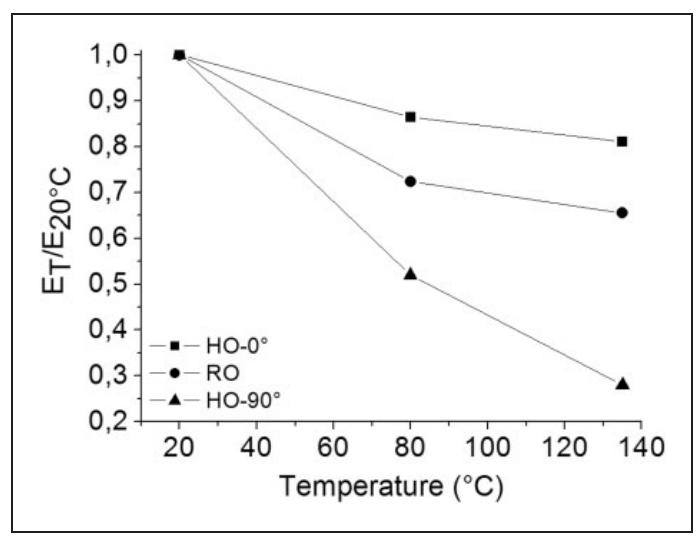

Figure 6. Evolutions of the relative Young's modulus of $\mathrm{HO}-0^{\circ}$, $\mathrm{RO}$, and $\mathrm{HO}-90^{\circ}$ samples at different temperatures.

been realized at different temperatures ranging from $20^{\circ} \mathrm{C}$ to $135^{\circ} \mathrm{C}$.

The analysis of the results shown in Figures 5 and 6 leads to the following remarks:

- For HO- $0^{\circ}$ oriented samples, the effect of temperature on Young's modulus is relatively limited due to the presence of oriented fibers parallel to the loading direction. Young's modulus decreases from 18.7 to $15 \mathrm{GPa}$ as the temperature increases from $20^{\circ} \mathrm{C}$ to $135^{\circ} \mathrm{C}$ (Figure 6). Concerning the failure stress, this effect has not been clearly established because of slipping of the sample during the tensile tests performed at $135^{\circ} \mathrm{C}$ (Figure 5).

- For HO- $90^{\circ}$ oriented samples, the effect of temperature on Young's modulus as well as on failure stress and failure strain is significant. A variation of the temperature from $20^{\circ} \mathrm{C}$ to $135^{\circ} \mathrm{C}$, leads to an abrupt decrease of the Young's modulus from 12.5 to $3.33 \mathrm{GPa}$ while failure stress decreases by $40 \%$ and failure strain increases by $60 \%$. It is important

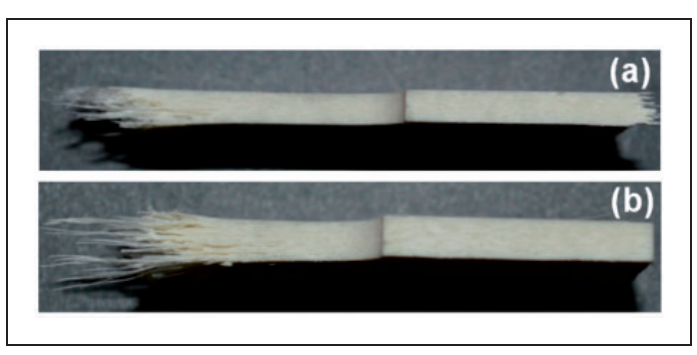

Figure 7. Macroscopic failure appearance of $\mathrm{HO}-90^{\circ}$ sample loaded at (a) $20^{\circ} \mathrm{C}$ and (b) $135^{\circ} \mathrm{C}$.

to notice that when the sample is loaded at $135^{\circ} \mathrm{C}$, the matrix is at rubbery state. This variation indicates also that the role of vinylester matrix in HO- $90^{\circ}$ specimens is very important. At macroscopic failure appearance (Figure 7) a pseudodelamination between the bundles of fibers seems to be favored.

As expected for RO samples, the influence of temperature on stiffness and failure properties is midway between the two other orientations $\left(\mathrm{HO}-0^{\circ}\right.$ and HO- $90^{\circ}$ ). Young's modulus decreases from 14.5 to $9.5 \mathrm{GPa}$ when the temperature increases from $20^{\circ} \mathrm{C}$ to $135^{\circ} \mathrm{C}$.

Figure 6 shows the relative Young's modulus defined by the ratio Young's modulus/Young's modulus at room temperature for $\mathrm{HO}-0^{\circ}$, $\mathrm{RO}$, and $\mathrm{HO}-90^{\circ}$. As expected, it decreases when the temperature is increased. However, this decrease for $\mathrm{HO}-0^{\circ}$ sample is less important than those of $\mathrm{RO}$ and $\mathrm{HO}-90^{\circ}$ samples. One can see that, in the case of HO- $90^{\circ}$ samples, the damage indicator (D) is hence strongly related to the effect of temperature.

\section{Fatigue behavior analysis}

Effect of the fiber orientation distribution. Figure 8 shows the normalized Wöhler curves obtained in tension-tension stress-controlled fatigue tests at a frequency of $10 \mathrm{~Hz}$ for $\mathrm{HO}-0^{\circ}, \mathrm{RO}$, and $\mathrm{HO}-90^{\circ}$ A-SMC samples. It can be noticed that in the case of RO samples for an applied stress equal to $0.44 \sigma_{\mathrm{r}(\mathrm{RO})}$, the fatigue life is about 50,000 cycles whereas the fatigue life is about $10^{6}$ cycles for an applied stress of $0.39 \sigma_{\mathrm{r}(\mathrm{RO})}$. So, a variation of $12 \%$ leads to a fatigue life about 20 times higher.

For RO-A-SMC samples, fatigue test performed at $34 \%$ of its ultimate stress, no failure is observed until $10^{7}$ cycles. For lower values, the specimen does not fail until $10^{7}$ cycles. It is obvious to note that for an applied stress corresponding to the endurance limit value for $\mathrm{HO}-0^{\circ}$ sample, $\mathrm{RO}$, and $\mathrm{HO}-90^{\circ}$ composites fail after less than 500 cycles. Thus, it can be establish that the 


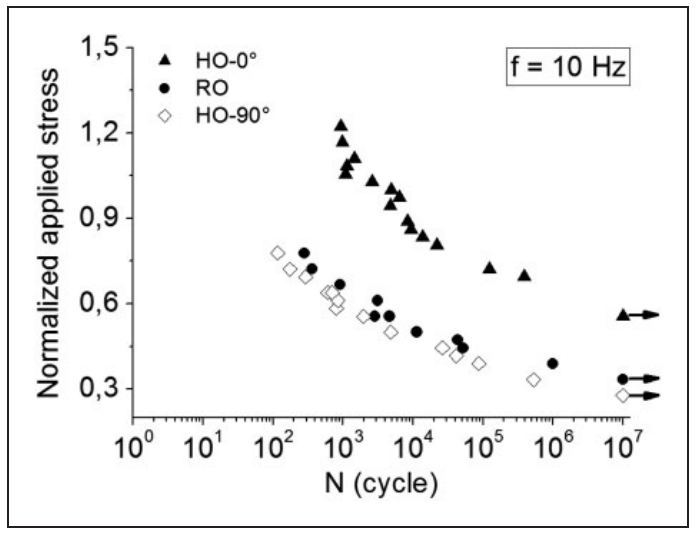

Figure 8. Normalized Wöhler curves for $\mathrm{HO}-0^{\circ}, \mathrm{RO}$, and $\mathrm{HO}-90^{\circ}$ samples at $10 \mathrm{~Hz}$.

Normalized value $=$ current value/average ultimate stress value $\left(\sigma_{r}\right)$ obtained for tests performed on RO-A-SMC.

fatigue life is strongly influenced by the distribution of fiber orientation. However, Figure 8 also shows that the fatigue life for $\mathrm{HO}-90^{\circ}$ samples is not significantly affected, compared to that of the RO samples. It can be established thus that for A-SMC composite, the fatigue design can be efficiently optimized through fiber orientation without critical reduction of material properties in the transverse direction.

Regarding to $\mathrm{RO}$ and $\mathrm{HO}$ samples at $10 \mathrm{~Hz}$, it can be noted that Wöhler curves show a bilinear form defining two different zones related to the high and low loading amplitude fatigue behavior. For RO and $\mathrm{HO}-90^{\circ}$ orientations high loading amplitude zone corresponds to fatigue life less than $10^{4}$ cycles for loading amplitude up to $0.47 \sigma_{\mathrm{r}(\mathrm{RO})}$, while for $\mathrm{HO}-0^{\circ}$ samples, this upper zone corresponds to fatigue life less than 30,000 cycles for stress values up to $0.75 \sigma_{\mathrm{r}(\mathrm{RO})}$. Under these values, the curves start deviating and tend to an asymptotic evolution defining a limit for which no failure is observed until $10^{7}$ cycles as described above.

Effect of frequency. Normalized Wöhler curves obtained from fatigue tests for the frequencies of $10,30,50$, and $100 \mathrm{~Hz}$ in the case of RO samples are shown in Figure 9. As it can be seen, there is small difference between the curves of 10,30 , and $50 \mathrm{~Hz}$ at low amplitude while at high loading amplitude, increasing frequency leads to Wöhler curves shifted to lower fatigue life.

For example, for an applied stress equal to 0.55 $\sigma_{\mathrm{r}(\mathrm{RO})}$, a variation of the frequency from 50 to $10 \mathrm{~Hz}$ leads to a fatigue life six times higher $\left(3 \times 10^{3}\right.$ and $1.8 \times 10^{4}$, respectively). On the other hand, it can be noted that even at a low value of the applied stress

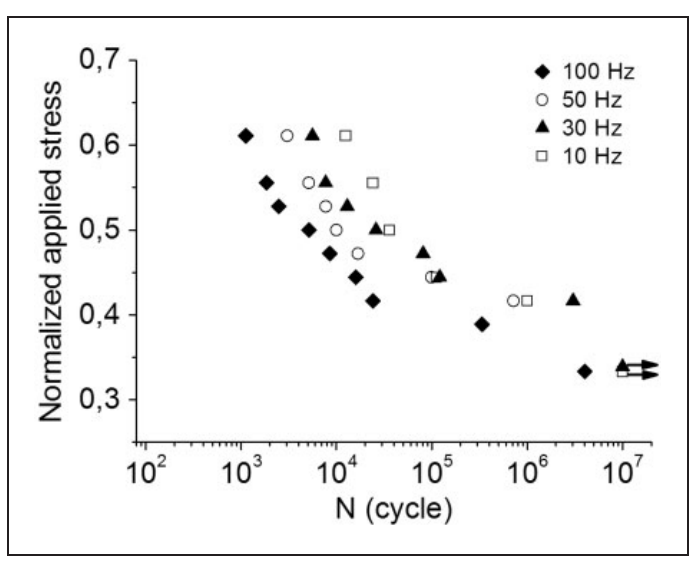

Figure 9. Normalized Wöhler curves at different frequencies for RO samples.

Normalized value $=$ current value/average ultimate stress value $\left(\sigma_{r}\right)$ obtained for tests performed on RO-A-SMC.

(applied stress equal to $\left.0.40 \sigma_{\mathrm{r}(\mathrm{RO})}\right)$ the fatigue life of the sample loaded at $100 \mathrm{~Hz}$ is about 40 times lower than the samples tested at 10,30 , and $50 \mathrm{~Hz}\left(2 \times 10^{4}\right.$ and around $10^{6}$ cycles, respectively). This ratio becomes more significant when the fatigue stress increases. It can be concluded that independently of the loading amplitudes, for values up to $50 \mathrm{~Hz}$, frequency has a determinant influence on the fatigue life. This phenomenon, in fact, is owing to the self-heating during fatigue test studied in the next paragraph.

\section{ITF and MF}

Depending on the loading conditions in terms of frequency and amplitude, the fatigue behavior induces self-heating. The latter influences the viscous behavior of the vinylester as a function of the level of the temperature rise with respect to material transition temperatures.

High frequency and applied stress lead to an increase of the self-heating phenomenon and cause an "induced thermal fatigue" (ITF). For low frequency, the fatigue behavior is mainly driven by the damage mechanisms occurring at the microscopic scale such as fiber-matrix interface debonding, micro-cracking of the matrix and pseudo-delamination between the bundles of fibers. This kind of phenomenon is introduced as "mechanical fatigue" (MF).

These two natures of fatigue behavior are analyzed and discussed in the following section on the basis of the temperature measurements for four loading conditions. Indeed, coupled effect between loading amplitude and frequency leads to a competition between induced self-heating and damage phenomenon. In order to illustrate the coupled effect of loading amplitude and 

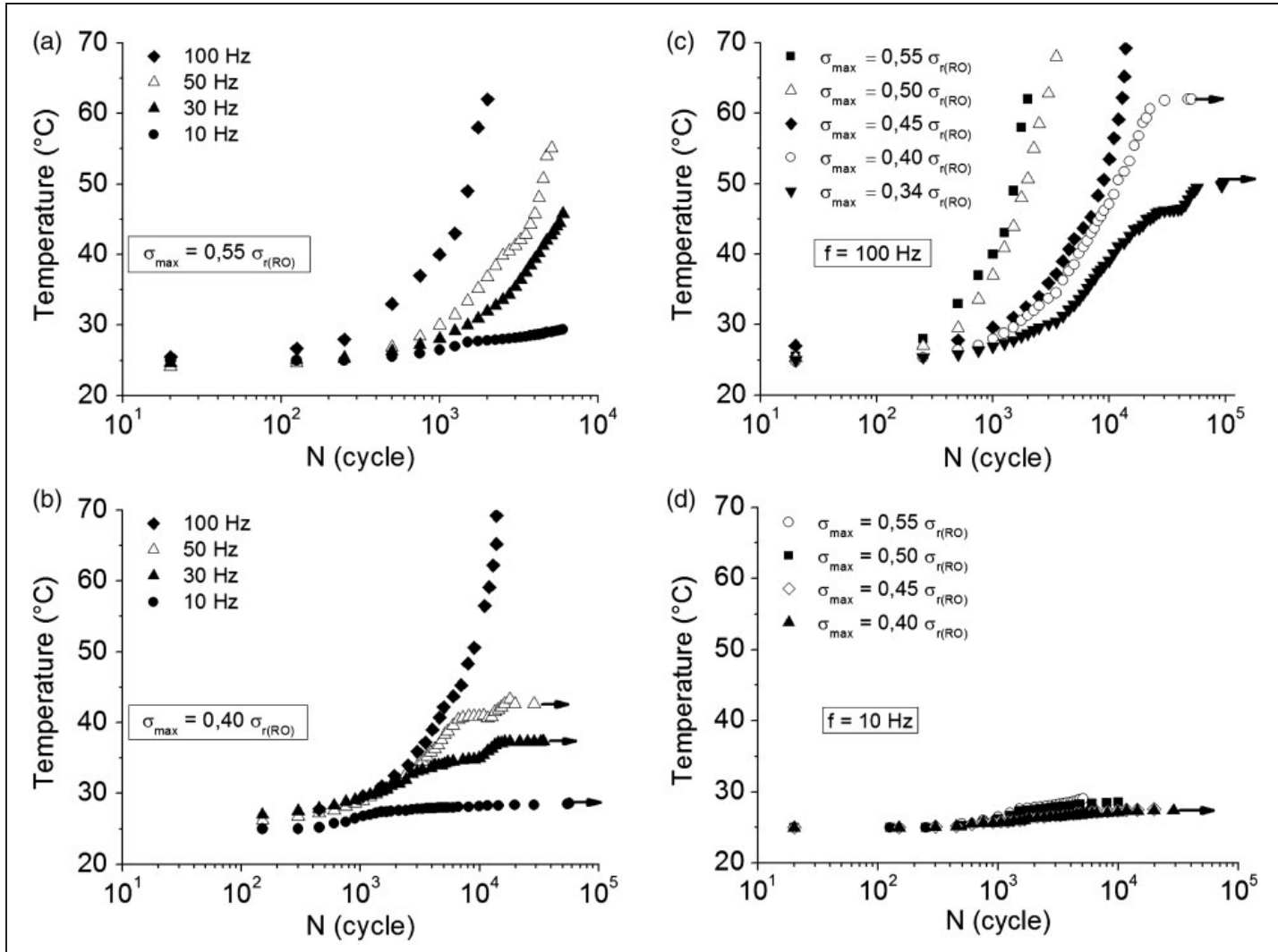

Figure 10. Temperature variation at different frequencies and amplitudes for RO samples: (a) $\sigma_{\max }=0.55 \sigma_{\mathrm{r}(\mathrm{RO})}$ and different frequencies, (b) $\sigma_{\max }=0.40 \sigma_{r(R O)}$ ultimate stress and different frequencies, (c) $f=100 \mathrm{~Hz}$ and different amplitudes and (d) $f=10 \mathrm{~Hz}$ and different amplitudes.

frequency, one can define two limit cases (a) and (d) and two intermediate cases (b) and (c):

a. High frequency and high loading amplitude

b. High frequency and low loading amplitude

c. Low frequency and high loading amplitude

d. Low frequency and low loading amplitude

\section{Induced self-heating}

Figure 10 illustrates the variation of temperature during fatigue tests in the case of RO samples at different frequencies and loading amplitudes. As it can be shown, no significant temperature changes are noticed until 200 cycles. For an applied stress equal to 0.55 $\sigma_{\mathrm{r}(\mathrm{RO})}$ (Figure 10(a)) at frequency of $100 \mathrm{~Hz}$, the temperature increases rapidly from room temperature to $62^{\circ} \mathrm{C}$ up to 2000 cycles while it remains almost constant for $10 \mathrm{~Hz}$ fatigue tests.

The same tendencies are observed concerning the applied stress: as shown in Figure 10(c) and (d) for both frequencies, the temperature increases more rapidly until fracture for high applied stresses. Moreover, at low applied stresses, a stabilization of the temperature can be observed until specific number of cycles which highlights the effect of heat exchange made possible by a lower rate of self-heating.

Moreover, in the range of temperature between $30^{\circ} \mathrm{C}$ and $45^{\circ} \mathrm{C}$, the curves (in Figure 10 (a) to (c)) show an acceleration of the induced self-heating phenomenon. Indeed, this range of temperature corresponds to the beginning of the modification of the physical state of the polyester matrix as it can be seen in Figure 3. This transition, as it was shown before, may correspond to the beta transition of vinylester under study.

\section{Influence of fatigue conditions on ITF and MF}

The study of the self-heating phenomenon together with the evolution of the relative Young's modulus is identified to be a good way to separate ITF and MF phenomena. Figure 11 shows the evolution of the relative Young's modulus together with the self-heating temperature evolution during tension-tension fatigue tests for the four limit fatigue test conditions described above: two applied maximum stresses equal to 0.55 

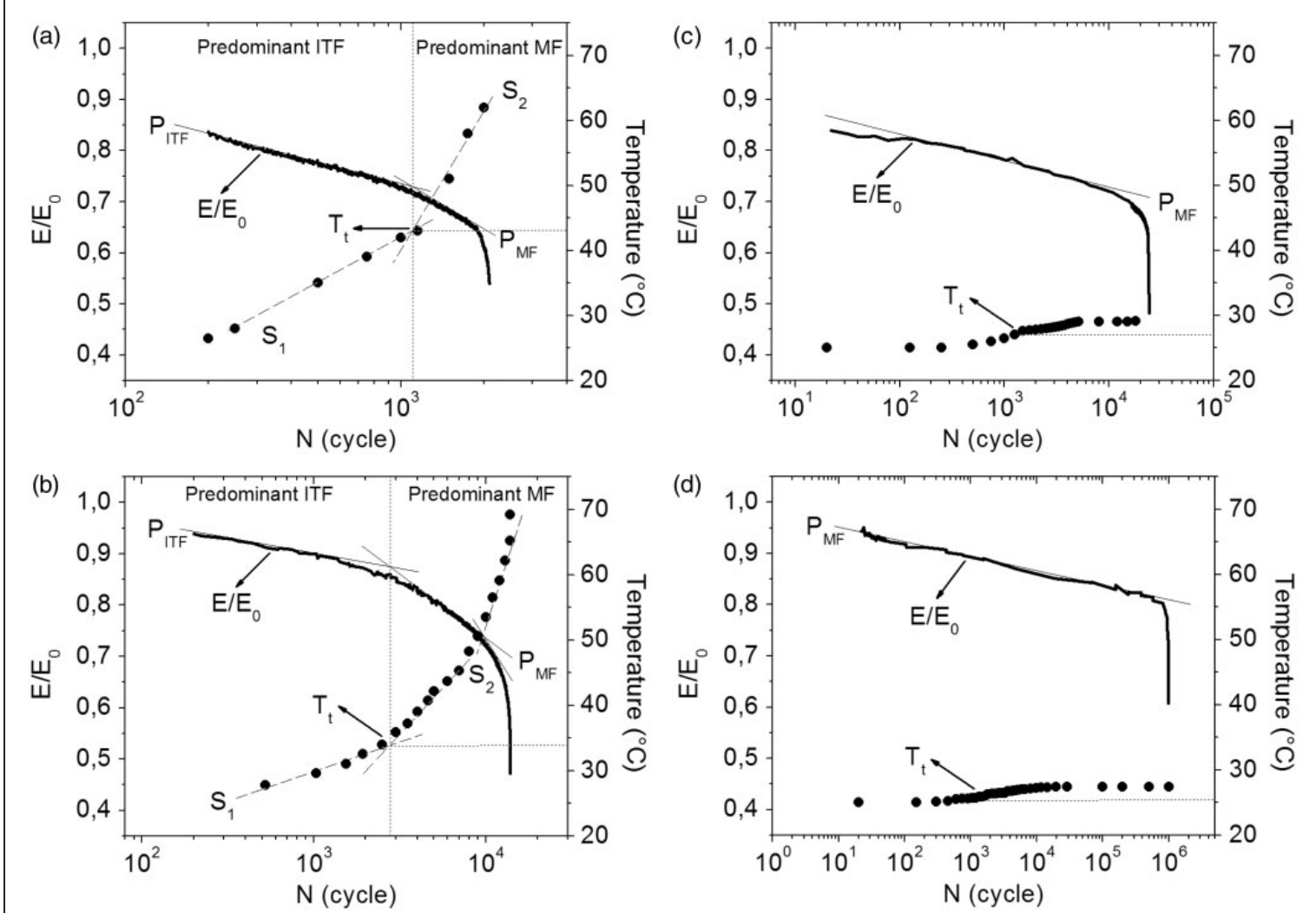

Figure II. Evolutions of the relative Young's modulus $\left(E / E_{0}\right)$ and the self-heating phenomenon during fatigue tests: $(a) f=I 00 \mathrm{~Hz}$ and $\sigma_{\max }=0.55 \sigma_{\mathrm{r}(\mathrm{RO})},(\mathrm{b}) \mathrm{f}=100 \mathrm{~Hz}$ and $\sigma_{\max }=0.40 \sigma_{\mathrm{r}(\mathrm{RO})},(\mathrm{c}) \mathrm{f}=10 \mathrm{~Hz}$ and $\sigma_{\max }=0.55 \sigma_{\mathrm{r}(\mathrm{RO})}$ and $(\mathrm{d}) \mathrm{f}=10 \mathrm{~Hz}$ and $\sigma_{\max }=0.40$ $\sigma_{\mathrm{r}(\mathrm{RO})}$.

$\sigma_{\mathrm{r}(\mathrm{RO})}$ and $0.40 \sigma_{\mathrm{r}(\mathrm{RO})}$ at different frequencies: $10 \mathrm{~Hz}$ and $100 \mathrm{~Hz}$

In what follows, one introduces two quantities, noted: $\mathrm{P}_{\mathrm{ITF}}$ and $\mathrm{P}_{\mathrm{MF}}$ defined respectively as the rate of stiffness reduction during the predominant ITF and the predominant MF stages (Figure 11). The rates represent the slope of the stiffness reduction curves.

On the other hand, one introduces two other terms: $\mathrm{S}_{1}$ and $\mathrm{S}_{2}$, which are defined respectively as the first and second rate of temperature increase during fatigue test as illustrated in Figure 11(a) and (b). Finally, a term $T_{t}$ is introduced as the specific temperature associated with a regime change of the temperature evolution between two stages as illustrated in Figure 11. For instance, in Figure $11(\mathrm{a}), \mathrm{T}_{\mathrm{t}}$ is about $43^{\circ} \mathrm{C}$.

For low amplitude and low frequency (case (d)) the RO-A-SMC exhibits a fatigue behavior mostly governed by the MF nature due to damage phenomenon, whereas for high amplitude and high frequency (case (a)), the ITF is the predominant nature of the RO-A-SMC fatigue behavior at low cycles. In this case, combined effect of high loading amplitude and high frequencies generates more intensive self-heating and damage phenomena. Indeed, for the test performed at $100 \mathrm{~Hz}$ and applied stresses equal to 0.55 $\sigma_{\mathrm{r}(\mathrm{RO})}$, the temperature increases up to $62^{\circ} \mathrm{C}$ (Figure 11(a)). This temperature corresponds to the end of the $\beta$-transition zone associated with the brittle-ductile transition for amorphous polymers. At this stage, the vinylester resin stiffness strongly decreases as shown in Figure 3. For these loading conditions (cases (a) and (b)), the polymer matrix is subjected to important thermally activated modifications of its physical state. . $^{6,15}$

Thus, the fatigue behavior and failure are not only due to the devolvement of a diffuse damage at the microscopic scale but also to the evolution of the viscous behavior of the matrix and the inherent brittleductile transition. So, for high frequency and amplitude tests (Figure 11(a)), the fatigue behavior is driven by both ITF and MF. Two different rates of stiffness reduction can be observed. During the first stage, the effect of damage is less important compared to the ITF. After a transition zone around 2000 cycles, damage becomes predominant (MF) and leads to the final failure. 
On the other hand, for the lower fatigue test conditions $\left(10 \mathrm{~Hz}\right.$ and applied stresses equal to $0.40 \sigma_{\mathrm{r}(\mathrm{RO})}$, see Figure 11(d)), self-heating remains very limited: only a temperature increases of $2.5^{\circ} \mathrm{C}$ is noticed (from $25^{\circ} \mathrm{C}$ up to $27.5^{\circ} \mathrm{C}$ ). The relative Young's modulus is not significantly affected by the self-heating. One observes a linear stiffness reduction prior to the failure. This sharp decrease is essentially due to the damage evolution and the fatigue behavior is mainly driven by the MF nature.

\section{Analysis of the ITF and MF kinetics}

One can notice that simultaneously with the temperature evolution, a stiffness reduction occurs according to two regimes characterized by two different slopes. The transition between the two regimes is clearly illustrated in Figure 11(a) and (b). The stiffness reduction is caused by the self-heating (softening) of the matrix and by the damage accumulation. It should be pointed that, at the end of some fatigue tests, a third stage can be observed which is accompanied by a very high temperature rise rate due to the rapid accumulation of the damage prior to the total failure, as shown in Figure 11(b).

In Figure 12, the relative values of $\mathrm{P}_{\mathrm{ITF}}, \mathrm{P}_{\mathrm{MF}}, \mathrm{S}_{1}$, and $S_{2}$ evolutions have been reported and plotted as a function of the applied stress and frequency. The relative values are defined as the ratio between the measured slope and the maximum value reached during fatigue test. As it can be observed in $\mathrm{P}_{\mathrm{ITF}}$ and $\mathrm{S}_{1}$ evolutions curves (Figure 12(a) and (c)) the self-heating phenomenon is highly favored by increasing of applied stress for both frequencies which confirms the effect of high applied stress on the self-heating kinetic. Obviously, this effect is more intensive for a high frequency. Indeed, for an applied stress equal to 0.34 $\sigma_{\mathrm{r}(\mathrm{RO})}$, the stiffness reduction rate increases by less than $10 \%$ while it increases by $100 \%$ for an applied stress equal to $0.60 \sigma_{\mathrm{r}(\mathrm{RO})}$. The evolution of $\mathrm{P}_{\mathrm{MF}}$ and $\mathrm{S}_{2}$ also confirms the effect of high applied stress and frequency on the stiffness reduction kinetic during the predominant MF stage ((Figure 12(b) and (d)).

On one hand, it can be noticed that, in the case of low frequency fatigue, there is no influence of the applied stress on the stiffness reduction kinetic during the first stage of fatigue life (low cycles). On the other hand, one can observe a rate augmentation of the stiffness reduction due to damage (MF during the second stage) of about $18 \%$ when increasing the applied stress from $0.34 \sigma_{\mathrm{r}(\mathrm{RO})}$ to $0.60 \sigma_{\mathrm{r}(\mathrm{RO})}$. At the same time, the temperature rise kinetic increases by about $7 \%$, which confirm the participation of the damage to the increase of the temperature.

Furthermore, Figure 12 allows getting more comprehensive data for the other loading amplitudes and
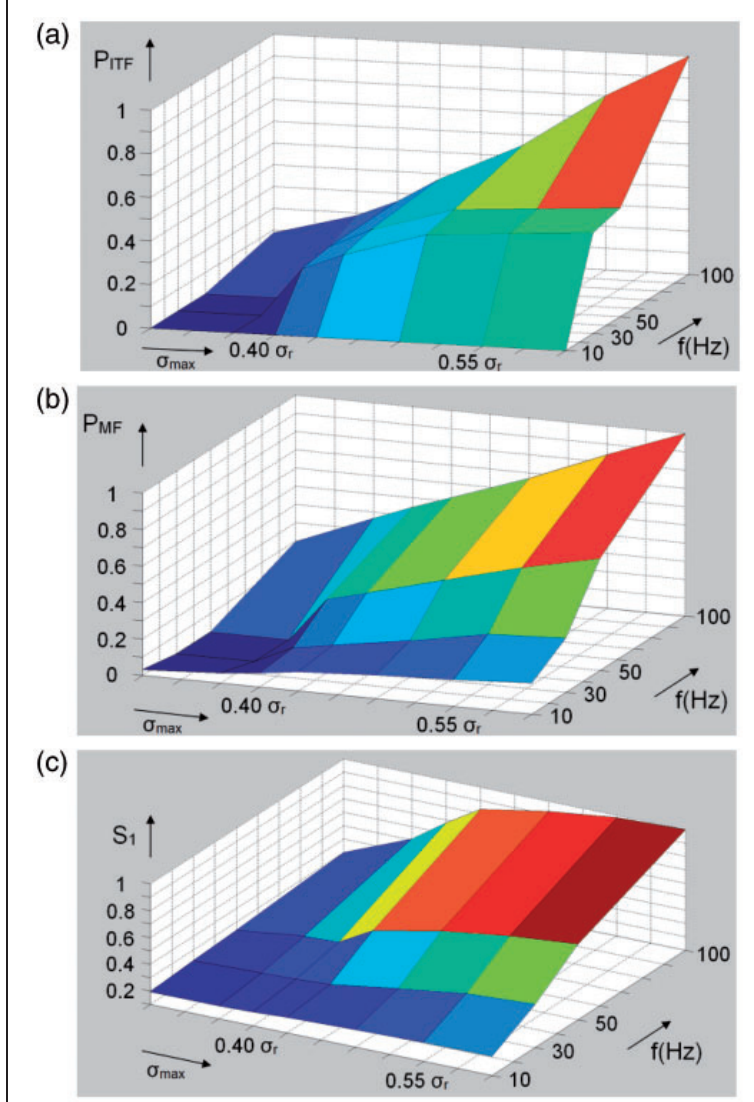

(d)

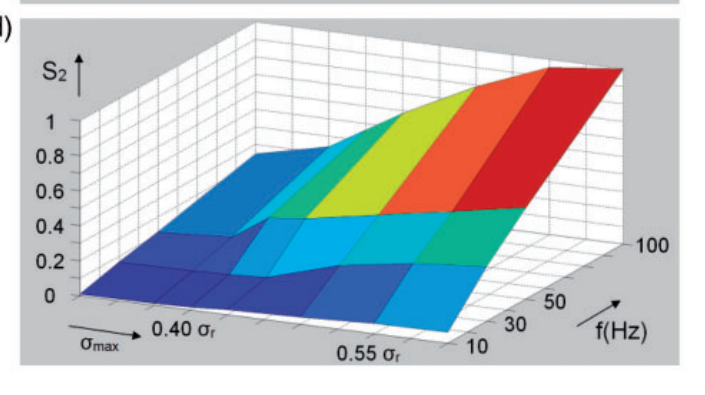

Figure 12. (a) $P_{I T F}$, (b) $P_{M F}$, (c) $S_{1}$, and (d) $S_{2}$ evolutions versus applied stress and frequency.

frequencies in order to get a more suitable quantitative and complete analysis of the self-heating effect coupled to damage. It also provides a cross-analysis of the coupled effect of amplitude and frequency which can be very suitable for automotive structure design.

In addition, the experimental data can enable the identification of a thermo-mechanical behavior law describing fatigue damage kinetic of A-SMC composites under various amplitudes and frequencies.

Finally, it can be concluded that both fatigue behavior and fatigue life of A-SMC composites are strongly influenced by a coupled effect between loading amplitude and frequency which induced thermal effect and progressive damage occurring at the microscopic scale. 


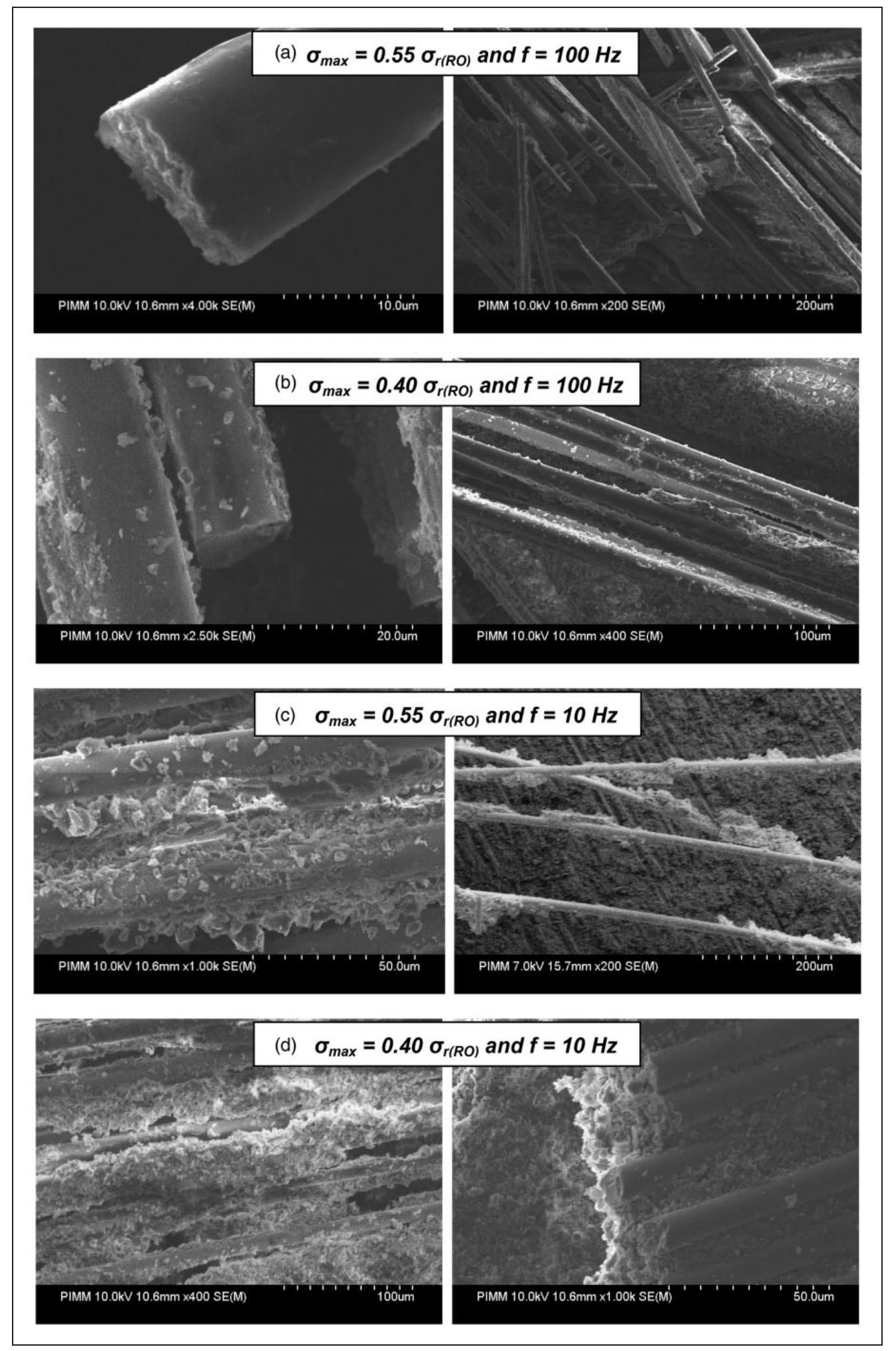

Figure 13. Fracture surface observation performed at different loading conditions: (a) $\sigma_{\max }=0.55 \sigma_{\mathrm{r}(\mathrm{RO})}$ and $\mathrm{f}=100 \mathrm{~Hz}$, (b) $\sigma_{\max }=0.40 \sigma_{\mathrm{r}(\mathrm{RO})}$ and $\mathrm{f}=100 \mathrm{~Hz},(\mathrm{c}) \sigma_{\max }=0.55 \sigma_{\mathrm{r}(\mathrm{RO})}$ and $\mathrm{f}=10 \mathrm{~Hz}$ and (d) $\sigma_{\max }=0.40 \sigma_{\mathrm{r}(\mathrm{RO})}$ and $\mathrm{f}=10 \mathrm{~Hz}$. 


\section{Fracture surface observation}

Fracture surface observations have been performed in order to emphasize the coupled effect of loading amplitude and frequency at microscopic scale. Figure 13 compares the fracture surfaces obtained for the four fatigue conditions described in ITF and MF section. SEM analysis highlights that, compared to lower frequency or applied stress, the fracture surface observed in the case of low applied stress and frequency $(0.40$ $\left.\sigma_{\mathrm{r}(\mathrm{RO})}, 10 \mathrm{~Hz}\right)$, bundles of fibers are pulled out from each other simultaneously with breakage of more surrounding matrix.

SEM observations and analysis on the samples tested at $100 \mathrm{~Hz}$, highlight more smooth debonded interfaces. Predominantly for the samples tested at $\sigma_{\max }=0.55 \sigma_{\mathrm{r}(\mathrm{RO})}$ and $100 \mathrm{~Hz}$, no surrounding matrix is observed on the debonded fiber/matrix interfaces. In fact, self-heating contributes to the matrix softening and brings it in beyond the brittle/ductile transition. Favored by high applied stress and frequency, a more ductile behavior during fatigue loading leads finally to a smoother debonding of the fiber-matrix interface as it can be observed in Figure 13(a) and (b). Furthermore, during fatigue tests performed at $10 \mathrm{~Hz}$, the self-heating remains limited leading to a more brittle fracture of the surrounding matrix and the related interfaces (Figure 13(c) and (d)).

\section{Conclusion}

An overall analysis of the fatigue behavior of A-SMC composite has been performed through the analysis of the coupled effect of loading amplitude and frequency. In order to highlight the ITF, the effect of frequency has been studied. At the same time, the effect of the loading amplitude allowed emphasizing the effect of damage kinetic on the nature of fatigue behavior of the A-SMC. Based on the results, the following concluding remarks are drawn to summarize the experimental findings:

- Whöler curves have been established for three loading directions and four frequencies. It has been shown that the fatigue life is strongly influenced by the distribution of fiber orientation. However, for transverse highly oriented material configuration $\left(\mathrm{HO}-90^{\circ}\right)$, the fatigue life is not significantly affected compared to that of the randomly oriented material configuration (RO).

- It has been shown that the $\beta$-transition characterizing the brittle-ductile transition for amorphous polymers and which is generally related to the mobility of the small segments of molecular chains plays an important role on the overall fatigue response of A-SMC composite notably for high frequency cyclic loading. In fact, the self-heating brings up the material close to the $\beta$-transition zone ranging from $35^{\circ} \mathrm{C}$ to $60^{\circ} \mathrm{C}$. The matrix behaves as a viscous media. The overall fatigue response exhibits an ITF nature which affects both stiffness reduction rate and fatigue life. This phenomenon is amplified by an increasing of the cyclic loading amplitude and frequency.

- It has been shown that for the high values of applied stress and frequency, the A-SMC exhibits an overall fatigue response mainly governed by the ITF nature during the first stage corresponding to low cycles. The MF nature becomes predominant during the second stage prior to the failure.

- For low applied amplitude and frequency loading conditions, no significant self-heating phenomenon has been observed and the overall fatigue response and fatigue life are mostly due to damage accumulation and the A-SMC exhibits predominantly a MF nature.

- Fracture surfaces observations evidenced the influence of the ITF on the fatigue overall response. Indeed, in the case of high values of frequency and applied stress, the surrounding matrix close to the fiber-matrix interface becomes ductile leading to a smooth interface debonding. On the other hand, low values of the frequency and applied stress lead to a brittle behavior of the surrounding matrix close to the interface showing a lot of matrix fragments around the debonded fibers.

- Evolution of the stiffness reduction and temperature increase and their related rates with respect to the number of cycle has been plotted as a function of frequency and loading amplitude. These evolution constitute an experimental database that can help formulating thermo-mechanical predictive models of the fatigue overall response.

\section{Declaration of Conflicting Interests}

The author(s) declared no potential conflicts of interest with respect to the research, authorship, and/or publication of this article.

\section{Funding}

The author(s) received no financial support for the research, authorship, and/or publication of this article.

\section{References}

1. Jendli Z, Meraghni F, Fitoussi J, et al. Multi-scales modeling of dynamic behaviour for discontinuous fibre SMC composites. Compos Sci Technol 2009; 69: 97-103.

2. Oldenbo M, Fernberg SP and Berglund LA. Mechanical behaviour of SMC composites with toughening and low 
density additives. Compos Part A Appl Sci Manuf 2003; 34: 875-885.

3. Le TH, Dumont PJJ, Orgéas L, et al. X-ray phase contrast microtomography for the analysis of the fibrous microstructure of SMC composites. Compos Part A Appl Sci Manuf 2008; 39: 91-103.

4. Palmer J, Savage L, Ghita OR, et al. Sheet moulding compound (SMC) from carbon fibre recyclate. Compos Part A Appl Sci Manuf 2010; 41: 1232-1237.

5. Shokrieh MM and Mosalmani R. Modeling of sheet molding compound compression molding under non-isothermal conditions. J Reinf Plast Compos 2014; 33: 1183-1198.

6. Shirinbayan M, Fitoussi J, Meraghni F, et al. High strain rate visco-damageable behavior of Advanced Sheet Molding Compound (A-SMC) under tension. Compos Part B-Eng 2015; 82: 30-41.

7. Guster C, Pinter G, Mosenbacher A and Eichlseder W. Evaluation of a simulation process for fatigue life calculation of short fibre reinforced plastic components. Procedia Eng 2011; 1: 2104-2109.

8. Quaresimin $\mathrm{M}$ and Guglielmino E. Influence of quick ageing on the fatigue behaviour of SMC composite materials. J Reinf Plast Compos 2001; 20: 147-165.

9. Bernasconi A, Davoli P, Basile A, et al. Effect of fibre orientation on the fatigue behaviour of a short glass fibre reinforced polyamide-6. Int J Fatigue 2007; 29: 199-208.

10. Fleckenstein J, Jaschek K, Büter A, et al. Fatigue design optimization of safety components made of SMC. Procedia Eng 2011; 10: 390-396.

11. Wang SS, Suemasu H and Chim ESM. Analysis of fatigue damage evolution and associated anisotropic elastic property degradation in random short-fiber composite. J Compos Mater 1987; 21: 1084-1105.

12. Handa K, Kato A and Narisawa I. Fatigue characteristics of a glass-fiber-reinforced polyamide. J Appl Polym Sci 1999; 72: 1783-1793.

13. Bellenger V, Tcharkhtchi A and Castaing P. Thermal and mechanical fatigue of a PA66/glass fibers composite material. Int J Fatigue 2006; 28: 1348-1352.

14. Zhou Y and Mallick PK. Fatigue performance of injection-molded short E-glass fiber reinforced polyamide-6,6.
II. Effects of melt temperature and hold pressure. Polym Compos 2011; 32: 268-276.

15. Esmaeillou B, Ferreira P, Bellenger V, et al. Fatigue behavior of polyamide 66/glass fiber under various kinds of applied load. Polym Compos 2012; 33: 540-547.

16. Arif M, Saintier N, Meraghni F, et al. Multiscale fatigue damage characterization in short glass fiber reinforced polyamide-66. Compos Part B-Eng 2014; 61: 55-65.

17. Mortazavian S and Fatemi A. Fatigue behavior and modeling of short fiber reinforced polymer composites including anisotropy and temperature effects. Int $J$ Fatigue 2015; 77: 12-27.

18. Atodrais DR, Putatundaa SK and Mallick PK. Fatigue crack growth model and mechanism of a random fiber SMC composite. Polym Compos 2004; 20: 240-249.

19. Launay A, Marco Y, Maitournam MH, et al. Cyclic behavior of short glass fiber reinforced polyamide for fatigue life prediction of automotive components. Procedia Eng 2010; 2: 901-910.

20. Renz R, Alstadt V and Ehrenstein GW. Hysteresis measurements for characterizing the dynamic fatigue of R-SMC. J Reinf Plast Compos 1988; 7: 413-434.

21. Jendli Z, Fitoussi J, Meraghni F, et al. Anisotropic strain rate effects on the fibre-matrix interface decohesion in sheet moulding compound composites. Compos Sci Technol 2005; 65: 387-393.

22. Jendli Z, Meraghni F, Fitoussi J, et al. Micromechanical analysis of strain rate effect on damage evolution in sheet molding compound composites. Compos Part A Appl Sci Manuf 2004; 35: 779-785.

23. Hour KY and Sehitoglu H. Damage development in a short fiber reinforced composite. J Compos Mater 1993; 27: 782-805.

24. Houston DQ, Hunt J and Jiang C. Fatigue performance of SMC composite material under different environmental damage and temperature conditions. In: Society of Plastics Engineers - 11th annual automotive composites conference and exhibition, ACCE 2011, MSU Management Education Center 811 W. Square Lake Road, Troy, MI 48084, USA, 13-15 September 2011. 